\title{
De Mãos Dadas na Rua Ainda é Muito Pouco. Classe Social e Acesso ao Poder
}

\author{
Célio Golin \\ Secretário Geral do Nuances - Grupo pela Livre Expressão Sexual \\ celiogolin@yahoo.com.br
}

Se hoje em dia é quase rotina vermos gueis e lésbicas andando de mãos dadas com seus pares nas ruas, em parques e em espaços fechados, podemos afirmar sem medo que essa realidade denota uma mudança de paradigma no 'mundo guei' e é claro, na sociedade brasileira. Neste artigo pretendo problematizar alguns pontos que entendo são chaves no debate. Um deles é como a classe social interfere nas posições políticas das pessoas, nos rumos do movimento e suas contradições. Como o capital condiciona a mobilidade dos sujeitos, considerando estética, local de moradia, gênero e cor. Como o gueto vem mudando, 'perdendo' espaço neste novo cenário.

Em 1991, ano de nascimento do Nuances - grupo pela livre expressão sexual, a rua era local de pegação, de flerte, de olhares suspeitos para o 'povo' LGBTT (sigla que não existia na época). Mas dois homens ou duas mulheres de mãos dadas ou abraçadas como vemos hoje, passados vinte anos, era algo impensável, e que efetivamente não acontecia. Se pensarmos em tempo histórico, entendo, que essa mudança de comportamento foi uma conquista e tanto: basta dirigirmos nosso olhar para cidades pequenas e interioranas, onde o tema da homossexualidade era proibido, e onde hoje as bichas e sapatas não pedem licença para se assumir.

Sei que muitos dirão que ainda existe muito preconceito e violência. Eu concordo. Porém os tempos são outros, e devemos estar atentos para essa nova conjuntura política e social. O próprio 'mundo guei' se transformou, inclusive com o surgimento de outras personagens que reivindicam novas identidades. É o caso das mulheres e homens trans, que não se reconheciam entre os conceitos daquela época. Para ilustrar as diferenças entre aquele cenário e o contemporâneo, tome-se o exemplo dos bares/ boates e outros locais que antes eram frequentados exclusivamente polos gueis e sapatas, os guetos. O gueto era local importante para encontros, namoros, confidências, lugar de anonimato. Atualmente os guetos vêm perdendo espaço, pois essa mudança de comportamento de romper com o armário e ocupar a via pública dá outro sentido ao antes necessário anonimato.

Nos guetos se construía um pacto de solidariedade, de pertencimento, pois a ruas, os espaços institucionais, bem mais que hoje, eram lugar de desaprovação e rejeição. Muitos que chegavam pela primeira vez em um gueto sentiam naquele espaço, um local de iguais, uma situação de conforto, por perceber que muitos e muitas que estava ali eram pessoas comuns como eles.

Nesta nova conjuntura, os guetos mudaram de certa forma o seu sentido, se antes eram locais de ferveção e sociabilidade, hoje são exclusivos para ferveção e putaria, onde o anonimato é quase a regra. Este não é uma particularidade do 'mundo guei', é claro, todas as tribos sempre vão ter seus espaços de transgressão, mas é evidente que no 'mundo guei', isto sempre foi e continua sendo um local de muita significação. Também temos que ressaltar que cada cidade encontra suas formas de sobrevivência/resistência e o que acontece em Porto Alegre tem suas peculariedades. O nuances publicou sete edições do Guia Gay de Porto Alegre, e isto faz sentido, pois não vemos outras tribos lançando seus guias de pegação.

Quero refletir, considerando esse contexto, sobre o debate em torno das questões que envolvem a vida desses sujeitos, debate que 
está, a meu ver, pouco aprofundado na sociedade brasileira, senão pelo próprio movimento LGBTT.

A mudança no comportamento de gueis, lésbicas, bissexuais, travestis e transexuais nos mostrou que precisamos pensar em outras questões envolvidas, já que a cidadania ainda é privilégio de poucos e poucas. Por exemplo, a questão da divisão da sociedade em classes sociais, permeada é claro, pela questão de gênero e raça, são fatores importantes na movimentação social.

É evidente que numa sociedade capitalista, se o dinheiro não é definidor de tudo, norteia muitas coisas, principalmente o acesso aos bens de consumo e suas consequências, interferindo diretamente nos locais sociais nos quais os sujeitos estão inseridos. É a partir da classe social que os sujeitos de forma hegemônica tomam suas posições frente ao mundo.

A mobilidade social, por exemplo, depende do dinheiro, e do conhecimento acumulado que está ligado diretamente à formação e ao acesso à informação. $\mathrm{O}$ capital proporciona e interfere de forma direta nas condições de poder frente ao mundo. Em se tratando dos LGBTT, somam-se a isso as questões que envolvem gênero e cor, que estão sempre associadas a uma maior legitimidade ou não.

É claro que isso não se dá somente com os homossexuais. Pessoas da periferia também estão submetidas a essas regras de mercado social. Nesses espaços se constroem outras lógicas de referência e de poder, e são com elas que os sujeitos dialogam sociamente.

Nos últimos anos a mídia e parte do próprio movimento LGBTT têm atuado de forma protagonista nesse cenário, muito ligado à ideia de consume. É visível que os gueis e as lésbicas que mais acessaram os direitos civis pertencem às classes media e alta, branca, com poder, inseridos no mercado de consumo. São esses LGBTTs, brancos e ricos, com capital simbólico que estão se posicionando, acessando e questionando o poder e obtendo direitos que até então eram somente exclusivos dos heterossexuais.

Questões como estética e local de moradia interferem nesse processo. A cobertura dada pela mídia nas Paradas LGBTT sempre evoca o poder de consumo e o 'bom gosto' das bichas. Os que não estão presentes nesse contexto higienizado, ou seja, pobres e negros, ainda estão na margem. O mesmo ocorre com as travestis, homens e mulheres trans. A estética, muito valorizada pelas bichas, também tem seu lugar de importância. Agora por exemplo, o estilo da moda é estar barbuda.

Como referência simbólica e concreta, podemos citar a presença dos gueis em aeroportos, que antes eram lugares de muito glamour, e as finas adoravam dar seu close, lugar onde se afirmavam socialmente a aumentavam seu capital simbólico. Agora os aeroportas, bem parecidos com rodoviárias não tem mais charme. Não tem mais a Varig com suas louças de porcelana, onde se podia escolher o prato no cardápio. As comissárias, aquelas bichas 'fazidas' desfilando por entre as poltronas com aquela impáfia que só nós temos. Isto pode parecer simplista e até vulgar, mas o poder também está contido nestes gestos/espaços. A elite hetero também esta incomodada com esta nova situação, dividindo espaço com os pobres na fila de embarque.

É evidente que a exclusão desses sujeitos também está ligada a questões morais que na sociedade brasileira são muito fortes. Se você é bicha, mas branca, e está inserida no mundo do consume e do shopping center, tudo bem! Mas se você é uma bicha fechativa e pobre, ai é um problema. É claro que a mudança de gênero, a 'fechação', em determinado momento, coisa muito comum no mundo das bichas, pode alterar esse local 
de legitimidade.

De onde venho, com quem ando, quais locais frequentam, são nessas situações que o dinheiro determina por onde poderei acessar e do que vou usufruir. A cidade/cidadania é proporcional ao local social no qual você existe. Enxergamos a cidade, os bens materiais, culturais, os serviços do Estado, o acesso à cultura, a educação num contexto construído pelas relações de poder, a partir de nossa existência de classe. A violência também aí se faz presente.

A mobilidade dentro da sociedade pode ser fruto de outros fatores, como beleza, talento individual. Exemplo disso é caso das travestis que se prostituem nas ruas. Mesmo tratandose de um cenário de margem, a beleza e o poder interferem no local geográfico e social: as travestis que batalham ao longo da Avenida Farrapos posicionam-se em locais diferentes de acordo com sua beleza e idade. Nos melhores pontos ficam as belas e novas, e as mais velhas e feias são escanteadas para os pontos distantes e de menor potencial comercial, local conhecido por fundão. São pessoas que acabam desenvolvendo uma forma de resistência, pois também na margem enfrentam uma situação totalmente adversa.

É claro que o capitalismo se sabota, pois os mais empoderados, os de cima, muitas vezes encontram-se intimamente em situação de desespero somente na marginalidade, e somente nela, encontram a possibilidade de realização de desejos. No seu mundo 'glamuroso', não há o tesão que alimenta seus prazeres. É como se diz: de noite todo o gato é pardo! Nesse universo do submundo os sujeitos criam personagens ou assumem o que realmente são, eventualmente até mudando de gênero. Ou não assumem nada, apenas sentem-se diferentes do dia-a-dia, quando têm outra postura.

Durante o dia passam despercebidos ou invisibilizados, na noite acabam sendo os, ou as protagonistas do palco. Mas também há aqueles que, pelo contrário, personagens que durante o dia são sujeitos de status social, na noite nesse mesmo contexto acabam assumindo um papel de coadjuvantes: são eles os clientes.

Mas não é somente à noite que a performance muda. Aqueles velhotes gueis, simpáticos que saem de casa e se dirigem a praças, bares ou saunas, no meio da tarde, enquanto os trabalhadores comuns trabalham, são sujeitos que mudam de comportamento, incorporam sua sexualidade, e a partir daí tornam-se ousados, atrevidos em suas atitudes frente ao mundo, dando outro significado as suas vidas.

Por outro lado, os garotos que saem de suas casas de forma anônima sem deixar rastro de desconfiança, em praças, ruas e saunas, incorporam atitudes que seus corpos expressam através duma linguagem repleta de códigos que somente poucos entendem. Dentro de um espaço urbano diverso, movidos pelo desejo, esses fulanos criam um universo único de transgressão rompendo as amarras sociais impostas pela moral.

Os significados existenciais vão estar pautados por essa condição de visível e invisível, conforme a sociedade ainda obrigar a usar máscaras. Tudo é relativo e o rompimento desse regramento vai ser influenciado pela condição econômica, pois os mundos individuais se constituem a partir de vários fatores, objetivos e subjetivos.

Estas questões são fundamentais para pensarmos em avançar politicamente, pois a classe social é determinante no momento de pensarmos em conquistar direitos (que já existem para a população heterossexual). Afinal, direitos para quem? Para quem já está inserido no mercado, ou para todas as pessoas, inclusive os e as moralmente indesejáveis?

O movimento LGBTT, organicamente formado pelos muitos/as militantes que batalham para a igualdade de direitos, ainda 
não perceberam essa discussão, pois, acham que pelo fato de sermos todos 'discriminados' mesmo de forma desigual, estaríamos todos no mesmo campo político. Sem contar que para uma grande parte desse/as militantes, a preocupação central é interesse pessoal, calcado em um narcisismo quase doentio.

Já sabemos que são múltiplos fatores que levam as pessoas a tomarem suas posições políticas e no caso da classe social, isto fica ainda mais evidente. Por isto é tão difícil construir uma identidade política e como consequência, por exemplo, elegermos representantes LGBTT no parlamento. Na hora que muitos LGBTTs optam por posições políticas/econômicas a classe social fala mais alto e isso se revela em períodos eleitorais.

\section{Estratégias Sempre em Disputa}

O parágrafo anterior talvez seja o pano de fundo pelo qual se percebe diferentes estratégias dentro e fora da militância, duas formas de intervenção política. Acho que dentro deste contexto de visibilidade que a pauta LGBTT tomou nos últimos anos, vieram à tona sentidos distintos de como se posicionar frente a status quo. Uns, com mais poder econômico e simbólico forçam para que as conquistas sejam a partir da norma da heterossexualidade, do capital, ou seja, temos que conquistar o que eles, os 'normais' têm, e ficar num mesmo patamar. Esta estratégia é conhecida como assimilacionista.

Outra linha política é a que questiona o poder e mesmo a normalidade da heterossexualidade, é neste campo o Nuances se filia, pois entende que o debate em torno da conquista de direitos vai além dos próprios, mas na contestação da dita normalidade da heterossexualidade que para o Nuances é mais uma construção ideológica de poder. Neste sentido esta posição é mais contestadora e aprofunda o debate em torno das reivindicações frente ao estado e sociedade de forma geral, pois também considera a classe social como um fator importante.

Esta posição vê na contestação da norma a possibilidade de abriram o debate em outro nível, trazendo inclusive os heteros para o debate e tendo a moral imposta à sexualidade como pano de fundo. Para o nuances, romper com as hierarquias de gênero está diretamente ligado ao cobate a homolesbotransfobia. Talvez seja por isto que os assimilacionistas não gostam de trazer para o debate estas questões, pois isto muda o sentido de estar na mundo, e neste caso o consumo e a classe social dita às regras em favor dos mesmos.

O submundo das bichas também incomodam as 'de cima', como pela própria nomenclatura utilizada como as palavras, bicha, viado, sapata etc., a flexão do verbo para o gênero feminino. Para o nuances usar estas palavras vai ao sentido de contestação, da ressignificação dos termos e assim disputar poder simbólico contido nas palavras. Além disto, reconhecer que neste universo, e principalmente na periferia a norma não faz sentido, pois não faz parte da vida destas pessoas.

No meio disto tudo, têm ainda os as militantes profissionais onde a preocupação central é hegemonizar o debate e como consequência o filão eleitoral deste novo nicho. Isto está presente em militantes ligados a partidos políticos. Para estes, questionar o padrão moral, heterossexualidade não é importante, mas sim vitimizar o máximo, colocar a culpa da homofobia no capital e tirar daí seus frutos eleitorais.

\section{Referência}

BENEDETTI, Marcos Renato. Toda Feita: gênero e identidade no corpo travesti. Rio de Janeiro: Garamond, 2005. 